студентов по курсу «Мировая художественная культура». Самара: Изд-во СамГПУ, 2001. С. 6-7.

16. Василевицкая О.В. Инсайт в структуре сознания // Сознание в актуальных измерениях: академический проект / отв. ред. Г.В. Акопов, Т.В. Семенова. Самара: ПГСГА, 2010. С. 104-113.

17. Алиев Ю.Б. Технология подготовки урока музыки // Методика преподавания музыки в общеобразовательных учреждениях: учебное пособие для студ. муз. фак. педвузов / Л.А. Безбородова, Ю.Б. Алиев. М.: Издательский центр «Академия», 2002. 416 с.

18. Абдуллин Э.Б., Николаева Е.В. Методика музыкального образования: учебник для студ. высш. пед. учеб. заведений / под общ. ред. М.И. Ройтерштейна. М.: Музыка, 2006. 336 с.

19. Фромм Э. Иметь или быть? // Величие и ограниченность теории Фрейда / Э. Фромм. М.: ООО «Фирма «Издательство АСТ», 2000. С. 185-437.

20. Горегляд В.Н. Хокку [Электронный ресурс] // Литературный энциклопедический словарь. - https:// literary_encyclopedia.academic.ru/7128/Хокку.

21. Виды синквейнов с примерами [Электронный pecypc] // Cinquain.ru: Синквейны. - http://cinquain.ru/ vidy-sinkvejnov-s-primerami.

22. Хаос [Электронный ресурс] // Философский словарь. - http://vslovare.info/slovo/filosofskiij-slovar/ haos.

\title{
ART WORKSHOP AS A FORM OF STUDENT'S ARTISTIC AND CREATIVE ACTIVITY
}

(C) 2018

Kalinina Larisa Yuryevna, candidate of pedagogical sciences, associate professor of Musical Education Department

Samara State University of Social Sciences and Education (Samara, Russian Federation)

Abstract. The paper describes an innovative form of organization of educational art-creative activity of students «art workshop». The author refers to the justification of the concept «art workshop» in the context of current ideas of the theory and practice art education. The contradiction between the content of student creativity in the XXI century and common in the practice of traditional forms of introducing them to the art may be withdrawn by the structuring activities in accordance with the phases of the creative process. Article submissions are a contribution to solving a larger problem of early diagnosis of giftedness, since supposedly this quality of the individual manifests itself more and more noticeable in terms of artistic and creative process. A definition of art workshop is given, its features are highlighted: polyart nature of children's activities, productive and aimed at understanding the meanings of reality through creative experience; engaging of elements of expression from the «arsenal» of modern composers, artists and poets. The implication is that the teacher is able to perceive the environment with immediate disciples, directing, but without limiting the collective creativity. This work makes it possible to orient teachers of music, fine arts teachers and teachers of additional education, as well as students of a pedagogical high school to making children be creative in accordance with their interests, abilities and their outlook.

Keywords: art education; music education; creativity of students; educational artistic and creative activity; synthesis of arts; art-composition; art-workshop; understanding meanings of reality through creative experience; modern art; modern student's world view.

УДК 378

Статья поступила в редакцию 13.01.2018

\section{КРИТЕРИАЛЬНО-ОЦЕНОЧНЫЙ АППАРАТ СФОРМИРОВАННОСТИ ПРОФЕССИОНАЛЬНО-ПРАВОВОЙ КОМПЕТЕНТНОСТИ БАКАЛАВРОВ СОЦИАЛЬНОЙ РАБОТЫ}

(C) 2018

Князева Анна Геннадьевна, старший преподаватель кафедры теории и истории социальной педагогики и социальной работы

Орловский государственный университет имени И.С. Тургенева (г. Орел, Российская Федерачия)

Аннотация. В статье поднимается вопрос об оценке сформированной в университете профессиональноправовой компетентности бакалавров социальной работы. Под профессионально-правовой компетентностью понимается профессиональное свойство выпускника по направлению «Социальная работа», способного эффективно решать профессиональные задачи в сфере правового регулирования социальной защиты населения. Уделено внимание актуальности этого профессионального качества у специалистов для современной России. Инструментом ее оценивания является критериально-оценочный аппарат, включающий мотивационный критерий (показатели: сформированность учебных, профессиональных мотивов, проявление интереса к праву); содержательно-когнитивный критерий (показатели: знание основ теории государств и права, основных отраслей российского права, объем, системность и осмысленность правовых знаний, знание нормативных актов правовых актов в сфере регулирования социальной защиты населения); креативно-деятельностный критерий (показатели: способность применять навыки и умения в решении профессионально-правовых задач, последовательность выполнения заданий, владение методами поиска, анализа и применения нормативных правовых актов в сфере социальной защиты населения); регулятивно-рефлексивный критерии (показатели: устойчивость в поведении, самооценка познавательной активности и последовательности выполнения заданий). Выполнен краткий обзор научных исследований по разработке критериев и показателей для оценки различных педагогических явлений. Автор останавливается на системном подходе в качестве методологиче- 
Князева А.Г.

Критериально-оценочный аппарат сформированности..

13.00.00 - педагогические науки

ской базы анализа критериально-оценочного аппарата, который предлагает рассматривать как интегративную целостность, включающую цель, объект, субъекты, предмет, содержание и результат. Критериальнооценочный аппарат сформированности профессионально-правовой компетентности бакалавров социальной работы может быть использован в системе повышения квалификации специалистов по социальной работе.

Ключевые слова: бакалавр социальной работы; профессионально-правовая компетентность; профессионально-правовая деятельность; мотивационный критерий; содержательно-когнитивный критерий; креативнодеятельностный критерий; регулятивно-рефлексивный критерий; показатели; диагностический инструментарий; системный подход; интегративная целостность.

Устойчивое положение России на новой ступени развития государственности обеспечивает реализация в полной мере конституционной нормы о социальной направленности ее политики. Гражданское общество при осуществлении взаимодействия с государством предъявляет конкретные требования к органам социальной защиты населения, к компетентности специалистов, исполняющих обязанности по предоставлению социальных услуг [1-4]. В свою очередь государство, формулируя социальный заказ высшему образованию, вводит стандартизированные нормативные требования к уровню подготовки выпускников по направлению «Социальная работа». Они отражают специфический характер профессиональной социальной работы современной действительности, связь с профессиональными стандартами, определяющими функционал специалиста по социальной работе, а также содержательное наполнение процесса подготовки бакалавров социальной работы в университете. Считаем, что именно правовая подготовка бакалавров социальной работы является залогом их успешной будущей профессиональной деятельности. В качестве аргумента укажем, во-первых, на тот факт, что социальное обеспечение, социальное обслуживание осуществляются на основании волеизъявления гражданина, что требует от специалиста применения процедурных действий юридического характера. Только знание и грамотное применение нормативных правовых актов позволяет специалистам социальных служб оказывать целенаправленную, своевременную поддержку категориям населения, указанных обширной законодательной базой. Во-вторых, процессы, происходящие в современном обществе, обусловливают, с одной стороны, появление новых категорий нуждающихся и необходимость разработки, внедрения правовых механизмов оказания им помощи специалистами - с другой. Кроме того, некодифицированное законодательство социальной защиты населения в России систематически изменяется [5], что требует от специалистов умения отслеживать новеллы в правовых актах, анализировать и применять их. И, в-третьих, эффективная правовая подготовка бакалавров социальной работы в университете способствует овладению системой правовых знаний и формированию умений по использованию нормативных правовых актов различных уровней, в том числе в нестандартных ситуациях. Сформированные в университете умения применять правовые знания и способность работать в непривычной обстановке являются необходимыми, на наш взгляд, качествами профессионалов, которые не только оказывают юридическую консультацию, но имеют дело с людьми, находящимися в стрессовой ситуации, имеющими проблемы с физическим и психическим здоровьем. Эти факторы детерминиру- ют осуществление правовой подготовки бакалавров в университете на таком уровне, который позволит уже специалистам по социальной работе не только показывать, но и применять правовые знания, творчески преобразовать алгоритмизированные действия, при этом производить рефлексию профессионального становления.

Результат присоединения России к Болонскому процессу в высшем образовании на сегодняшний день отражен в ситуации, в которой образовательные организации высшего образования обладают академическими свободами, нормативно-правовое обеспечение образовательного процесса четко прописывает результаты образования, однако отсутствуют нормативы самого содержания образования, а также критерии его оценки. Таким образом, именно преподаватель при составлении рабочей программы определяет наполнение дисциплины и аппарат сформированности разработанных им же самим транскриптеров. Отсюда вытекает предъявление высоких этических, профессиональных требований к уровню его подготовки, умению не только использовать зарубежный опыт профессионального образования, но и «переводить» его на рельсы российской системы подготовки специалистов социальной сферы. Так, ОК-4 и ПК-5 ФГОС ВО по направлению подготовки 39.03.02 Социальная работа [6], определяют в качестве результатов освоения программы бакалавриата способности использовать как правовые знания в различных сферах жизнедеятельности в целом, так и нормативные правовые акты федерального и регионального уровней для правового регулирования социальной защитой граждан в частности. Таким образом, профессиональная правовая подготовка бакалавров социальной работы в университете через призму компетенций позволяет нам говорить об их профессионально-правовой компетентности. Под профессионально-правовой компетентностью бакалавров социальной работы мы понимаем профессиональное качество выпускника по направлению подготовки «Социальная работа», проявляющееся в способности к эффективному решению профессиональных задач в сфере правового регулирования социальной защиты населения [7]. В необходимости формирования профессионально-правовой компетентности бакалавров социальной работы убеждают и цифры. Например, по данным Федеральной службы государственной статистики, в России на 2016 год в стационарных учреждениях социального обслуживания для граждан пожилого возраста проживало 256990 человек, на 1 января 2017 года в центрах и отделениях социального обеспечения на дому граждан пожилого возраста и инвалидов состояло 1138038 человек [8]. Очевидно, это граждане, нуждающиеся в правовой консультации по вопросам 
пенсионного обеспечения, имущественным спорам, составления завещания. В то же время профессионально-правовой деятельностью специалиста по социальной работе охвачено значительное количество иных категорий населения. Подчеркиваем, в рамках указанного направления подготовки мы формируем именно профессионально-правовую компетентность и именно у бакалавров социальной работы. Правильно и необходимо наличие юристов в социальной сфере, однако специалисты по социальной работе являются тем первичным звеном, с которым имеют дело получатели социальных услуг, социальной помощи, от которых получают базовую правовую информацию и дальнейшее профессионально-правовое консультирование. Поэтому формирование профессионально-правовой компетентности бакалавров социальной работы в университете является неотъемлемой частью формирования их общей профессиональной компетентности. Тем актуальнее является вопрос о критериально-оценочном аппарате сформированности профессионально-правовой компетентности бакалавров социальной работы в университете.

В связи с этим анализ научной литературы показал, что системе критериев и оценивания сформированности какого-либо новообразования в педагогике высшей школы уделено внимание. Так, разработан критериально-оценочный аппарат сформированности профессиональных компетенций у будущих специалистов по связям с общественностью [9], готовности студентов-лингвистов к межкультурному взаимодействию [10], правового сознания у студентов высших учебных заведений [11], организации самостоятельной работы студентов медицинских специальностей вузов [12], правовой компетентности курсантов [13], этноэстетической культуры студентов университета [14]. В исследованиях, посвященных профессиональной подготовке будущих специалистов по социальной работе, приведен критериальнооценочный аппарат сформированности субъектной позиции будущего специалиста по социальной работе [15], культуры профессионально-проектной деятельности [16], готовности к сопровождению детей, оставшихся без попечения родителей [17], готовности по использованию средств физической культуры в работе с пожилыми людьми [18]. Изучение научнопедагогических источников показало, что при разработке критериально-оценочного аппарата искомого явления у студентов, обучающихся по направлению подготовки «Социальная работа», прослеживаются небезынтересные тенденции. Первая - отбор критериев осуществляется на основе структурных компонентов исследуемого явления. Чаще всего выделяются мотивационный, когнитивный, деятельностный, операциональный, рефлексивный, личностный с различными вариациями. Таким образом, объект «расходится» на составные части и, как показывает анализ, исследователю недостаточно инструментария для его синтезирования, что негативно отражается на общем представлении об этом объекте и в конечном счете на результатах опытно-экспериментальной работы в целом. Вторая - влияние теоретико-методологической позиции исследователя. Природа критериев имеет объективный характер, они не могут быть вы- думаны, поскольку отражают сущность исследуемого явления, поэтому при разработке показателей какого-либо критерия показательна приверженность автора к определенной научной школе. Например, в качестве показателей когнитивного критерия в ряде работ определены алгоритмичность, эвристичность, «творческость», сопоставимые уровням усвоения учебного материала, разработанные В.П. Беспалько [19], в других - воспроизведение, узнавание, применение, воспроизведение системы понятий, применение системы понятий, соответствующие дидактике М.Н. Скаткина, И.Я. Лернера [20], или - прочность, осознанность, действенность, глубина, предложенные Ю.К. Бабанским [21]. Поэтому, определяя критерии и показатели сформированности профессионально-правовой компетентности бакалавров социальной работы, мы преследовали цель, во-первых, найти методологическую основу, с помощью которой можно получить целостное представление о сущности, содержании и структуре исследуемой компетентности, включающей мотивационный, когнитивный, деятельностный и рефлексивный компоненты. Во-вторых, для соблюдения «научной чистоты» проведенной опытно-экспериментальной работы показатели критериев согласовать с требованием конкретизации, полноты, целостности, информативности и однозначности толкования [22].

Критерий в качестве средства измерения, выбора альтернативы рассматривает И.А. Ивлиева [23]; образцом, ориентиром он выступает для О.Н. Башкировой [24]; отличительным признаком, характеризующим предмет, является он с точки зрения Г.В. Алферовой [25], а толковый словарь определяет критерий как «мерило оценки» [26, с. 307]. Критериальнооценочный аппарат сформированности профессионально-правовой компетентности бакалавров социальной работы в университете способствует достижению поставленной цели - формирование профессионально-правовой компетентности бакалавров социальной работы, помогает в анализе потенциальных отклонений от установленного образца в разработанной нами теоретической модели.

Мотивационный критерий фиксирует мотивацию к овладению основами профессионально-правовой деятельности, готовности ее совершенствовать, наделять смыслами профессию и осмысливать свое нахождение в ней. Оценивается по сумме таких показателей, как сформированность учебных, профессиональных мотивов, самостоятельность и активность на занятиях, а также проявление интереса к праву. Содержательно-когнитивный критерий показывает уровень систематизации профессионально-правовых знаний, умений, приемов взаимодействия как в процессе обучения, так и в решении учебно-профессиональных задач. В процессе измерения этого критерия учитываются следующие показатели: знание основ теории государства и права, отраслей российского права, объем, системность, осмысленность правовых знаний, знание нормативных правовых актов в сфере регулирования социальной защиты населения. Креативно-деятельностный критерий отражает качество реализации форм и методов, ориентированных на формирование профессионально-правовой 
Князева А.Г.

компетентности бакалавров социальной работы. Показателями являются способность применять навыки и умения в решении профессионально-правовых задач, последовательность их выполнения, владение методами поиска, анализа и применения нормативных правовых актов в сфере социальной защиты населения. Регулятивно-рефлексивный критерий характеризует сформированность навыков эмоционально-волевой регуляции, самостоятельное оценивание личностного и профессионального совершенствования. Его показатели: устойчивость в поведении, самооценка познавательной активности и последовательности выполнения заданий.

Определение критериально-оценочного аппарата сформированности профессионально-правовой компетентности бакалавров социальной работы как системы позволяет характеризовать его как интегративную целостность, элементы которой находятся во взаимосвязи и взаимодействии, а также не обладают качествами, присущими самой системе. Базовым элементом критериально-оценочного аппарата является цель, которая объединяет и подчиняет остальные компоненты системы. Целью критериальнооценочного аппарата формирования профессионально-правовой компетентности бакалавров социальной работы является детальное информирование и его оценивание посредством представления о состоянии изучаемого явления, происходящих в нем количественно-качественных изменений. Объектом критериально-оценочного аппарата является процесс формирования профессионально-правовой компетентности бакалавров социальной работы. Субъектами являются будущие специалисты по социальной работе и исследователь. Предметом мы определяем модель и методику формирования профессионально-правовой компетентности бакалавров социальной работы в университете. Содержанием работы критериальнооценочного аппарата считаем сбор информации с помощью диагностического инструментария на всех этапах эксперимента, ее систематизацию, интерпретацию, оценку, внесение корректив, выстраивание перспектив дальнейшей исследовательской деятельности. Результатом использования критериальнооценочного аппарата является, во-первых, целостное представление о сущности, содержании и структуре формируемого в университете профессионального качества бакалавров, во-вторых, формулирование выводов и рекомендаций для использования разработанной модели и реализованной методики формирования профессионально-правовой компетентности бакалавров социальной работы. Применение системного подхода в отношении критериально-оценочного аппарата позволяет объединить уже проанализированные, имеющие количественное и качественное выражение, мотивационный, когнитивный, деятельностный, рефлексивный компоненты профессионально-правовой компетентности бакалавров социальной работы.

Уяснению соответствия показателей критериям помогает информативный, объективный, валидный и надежный диагностический инструментарий. Так, для оценки выраженности мотивационного критерия мы использовали «методику выбора профессии»
Р.В. Овчаровой, методику незаконченных предложений. Для определения отношения к праву специалиста по социальной работе стандартной методики нами обнаружено не было, поэтому в соответствии с целями исследования методика Д.С. Безносова «отношение к праву» [27] была модифицирована с помощью вопросов, имеющих отношение к профессионально-правовой деятельности специалистов по социальной работе. Показатели содержательно-когнитивного критерия обобщались тестированием, опросами, контрольными работами и коллоквиумами, анализом продуктов квазипрофессиональной и учебно-профессиональной деятельности студентов. Оценка креативно-деятельностного критерия осуществлялась методом кейсов, изучением способов решений профессионально-правовых задач, опросами, методом экспертных оценок, тестом «Креативность» Н.Ф. Вишняковой. Опросник «Исследование волевой саморегуляции» А.В. Зверькова, Е.В. Эйдмана, методика «Диагностика рефлексивности» (опросник А.В. Карпова), а также беседы и методика незаконченных предложений оценивали регулятивнорефлексивный критерий. Сбор информации осуществлялся в привычных для экспериментальных групп условиях с учетом особенностей организации образовательного процесса, максимального обеспечения психологического комфорта для проявления способности к оценочной и самооценочной деятельности. Приведенное описание диагностических средств не исчерпывает их возможного разнообразия, но их достаточно для получения конкретной информации в полном объеме для построения целостной картины о сущности, содержании и динамике формируемой профессионально-правовой компетентности бакалавров социальной работы [28].

Критериально-оценочный аппарат сформированности профессионально-правовой компетентности бакалавров социальной работы эффективен при рассмотрении его в качестве целостной системы критериев, показателей, диагностического инструментария, что гарантирует интегративность и адекватность информации об исследуемом педагогическом явлении. Целесообразное использование критериальнооценочного аппарата сформированности рассматриваемого профессионального качества выпускника университета по направлению подготовки «Социальная работа» позволит найти новые пути его формирования, а также может быть полезен в системе повышения квалификации специалистов по социальной работе.

\section{Список литературы:}

1. Постановление Пленума Верховного Суда РФ «О практике рассмотрения судами дел, связанных с реализацией прав граждан на трудовые пенсии» от 11.12.2012 № 30 // Российская газета. № 295, 21.12.2012.

2. Определение Верховного Суда РФ от 28.03.2016 № 18-КГ16-7 [Электронный ресурс] // КонсультантПлюс. - http://consultant.ru.

3. Решение Верховного Суда РФ «Об оспаривании отдельных пунктов Правил предоставления льгот инвалидам и семьям, имеющим детей-инвали- 
дов, по обеспечению их жилыми помещениями, оплате жилья и коммунальных услуг» от 13 марта 2014 г. № АКПИ13-1200 // Архив решений арбитражных судов и судов общей юрисдикции. http://sudrf.kodeks.ru/rospravo/document/499091132.

4. Постановление Пленума Верховного Суда РФ «О некоторых вопросах рассмотрения судами споров по оплате коммунальных услуг и жилого помещения, занимаемого гражданами в многоквартирном доме по договору социального найма или принадлежащего им на праве собственности» от 27.06.2017 № 22 // КонсультантПлюс. - http://consultant.ru/document/ cons_doc_LAW_218822.

5. Мартынова П.И., Князева А.Г. Правовое обеспечение социальной защиты населения как условие развития российского общества // Наука XXI века: актуальные вопросы, проблемы и перспективы: материалы международной (заочной) научно-практической конференции / под общ. ред. А.И. Вострецова. Душанбе, Нефтекамск: РИО НИЦ «Мир науки», 2017. С. $280-286$.

6. Приказ Министерства образования и науки РФ «Об утверждении федерального государственного образовательного стандарта высшего образования по направлению подготовки 39.03.02 Социальная работа (уровень бакалавриата)» от 12 января 2016 года № 8 // Официальный интернет-портал правовой информации. 12.02.2016, № 0001201602120037.

7. Князева А.Г. К вопросу о понятии «профессионально-правовая компетентность бакалавров социальной работы»: педагогический аспект. Социальное взаимодействие в различных сферах жизнедеятельности: материалы VII международной научно-практической конференции / отв. ред. Е.И. Бражник, Н.Н. Суртаева. СПб.: Изд. РГПУ им. А.И. Герцена, 2017. C. 199-202.

8. Уровень жизни [Электронный ресурс] // Федеральная служба государственной статистики. http://gks.ru.

9. Гридина В.В. Диагностика и оценивание эффективности технологии формирования профессиональных компетенций у студентов - будущих специалистов по связям с общественностью в процессе обучения дисциплине «Религиоведение» // Известия Самарского научного центра Российской академии наук. 2013. Т. 15, № 2 (2). С. 319-322.

10. Мажар Е.Н. Критерии оценки готовности студентов-лингвистов к межкультурному взаимодействию в контексте практико-ориентированного подхода // Ученые записки. Электронный научный журнал Курского государственного университета. 2017. № 2 (42). С. 173-179.

11. Цекатунова Л.Б. Критериально-диагностический инструментарий оценки сформированности правового сознания студентов высших учебных екатунова // Фундаментальные исследования. 2015. № 2 (часть 2). С. 1314-1317.

12. Зайцева О.Н. Критериально-уровневая характеристика организации самостоятельной работы студентов медицинских вузов // Теория и практика образования в современном мире: материалы III международной научной конференции (г. Санкт-Петербург, май 2013 г.). СПб.: Реноме. 2013. С. 151-153.
13. Бондарева О.А. Правовая компетентность курсантов ведомственных вузов по основным образовательным программам высшего образования, реализуемым в интересах обеспечения законности и правопорядка // Ученые записки Орловского государственного университета. Серия «Гуманитарные и социальные науки». 2017. № 2 (75). С. 207-212.

14. Алдошина М.И. Критериальный аппарат сформированности этноэстетической культуры студентов университета // Актуальные инновационные исследования: наука и практики. 2012. № 3. С. 6-11.

15. Черкасова Ю.А. Становление субъектной позиции будущего специалиста по социальной работе в практическом обучении: дис. ... канд. пед. наук. М., 2013. $186 \mathrm{c}$.

16. Васильева Т.В. Формирование в вузе культуры профессионально-проектной деятельности бакалавров социальной работы: дис. ... канд. пед. наук. М., 2015. 203 c.

17. Голенкова О.В. Формирование в вузе профессиональной готовности бакалавра по направлению подготовки «Социальная работа» к сопровождению детей, оставшихся без попечения родителей: автореф. дис. ... канд. пед. наук. М., 2015. 179 с.

18. Прядко Л.А. Формирование у будущих социальных работников готовности к использованию средств физической культуры в работе с пожилыми людьми: дис. ... канд. пед. наук. Омск, 2013. 190 с.

19. Беспалько В.П. Основы теории педагогических систем. Воронеж: Изд-во Воронеж ун-та, 1977. $204 \mathrm{c}$.

20. Скаткин М.Н. Дидактика средней школы / под ред. М.Н. Скаткина, И.Я. Лернера. М., 1975. 267 с.

21. Бабанский Ю.К. О дидактических основах повышения эффективности обучения // Народное образование. 1986. № 11. С. 105-111.

22. Белякова Е.Г., Строкова Т.А. Психолого-педагогический мониторинг: учебное пособие. Электронное издание. Тюмень: Издательство Тюменского государственного университета, 2015. 240 с.

23. Ивлиева И.А. Методолого-теоретические основы оценочно-критериальной системы многоуровневой подготовки: дис. ... д-ра пед. наук. СПб., 1998. $471 \mathrm{c}$.

24. Башкирова О.Н. Формирование готовности студентов педвуза к использованию воспитательных возможностей учебного процесса: дис. ... канд. пед. наук. Калуга, 2008. 184 с.

25. Алферова Г.В. Формирование у студентов педвуза готовности к профессиональному общению с родителями: дис. ... канд. пед. наук. Волгоград, 1996. $178 \mathrm{c}$.

26. Ожегов С.И., Шведова Н.Ю. Толковый словарь русского языка: 80000 слов и фразеологических выражений. 4-е изд., дополненное. М.: А ТЕМП, 2004. 944 c.

27. Безносов Д.С. Отношение к праву как проявление правового сознания курсантов вузов МВД РФ: дис. ... канд. псих. наук. СПб., 2004. 234 с.

28. Князева А.Г. Формирование профессионально-правовой компетентности бакалавров социальной работы в университете: дис. ... канд. пед. наук. Орел, 2017. $176 \mathrm{c}$. 


\title{
CRITERIA-EVALUATION APPARATUS OF BACHELORS' PROFESSIONAL AND LEGAL COMPETENCE DEVELOPMENT
}

(C) 2018

Knyazeva Anna Gennadyevna, senior lecturer

of Theory and History of Social Pedagogy and Social Work Department

Orel State University named after I.S. Turgenev (Orel, Russian Federation)

Abstract. The paper raises a question of assessing professional and legal competence of bachelors majoring in social work at university. Professional and legal competence is a professional property of a graduate in the field of social work, which can effectively solve professional problems in the field of legal regulation of social protection of the population. Attention is paid to the relevance of this professional quality among specialists for modern Russia. The instrument of its evaluation is the criteria-evaluation apparatus, including motivational criterion (indicators: educational, professional motives, interest in law); content-cognitive criterion (indicators: knowledge of the theory of states and law, main branches of Russian law, knowledge of legal acts in the field of regulation of social protection of the population); creative activity criterion (indicators: ability to apply skills and abilities for solving professional and legal problems, sequence of tasks, knowledge of methods of search, analysis and application of normative legal acts in the field of social protection of the population); regulatory and reflexive criteria (indicators: stability in behavior, self-assessment of cognitive activity and sequence of tasks). The paper contains a brief review of research on the development of criteria and indicators for assessing various pedagogical phenomena. The author focuses on the systematic approach as a methodological basis for the analysis of the criteria-evaluation apparatus, which proposes to be considered as an integrative integrity, including the purpose, object, subjects, subject, content and result. Criteriaevaluation apparatus of bachelors' professional and legal competence development can be used in the system of advanced training of specialists in social work.

Keywords: bachelor of social work; professional and legal competence; professional and legal activity; motivational criteria; content-cognitive criteria; creative-activity criteria; regulatory-reflexive criteria; indicators; diagnostic tools; systematic approach; integrative integrity.

\section{ФОРМИРОВАНИЕ ПРОФЕССИОНАЛЬНЫХ КОМПЕТЕНЦИЙ СТУДЕНТОВ НАПРАВЛЕНИЯ ПОДГОТОВКИ «ПЕДАГОГИЧЕСКОЕ ОБРАЗОВАНИЕ» ПРОФИЛЕЙ «НАЧАЛЬНОЕ ОБРАЗОВАНИЕ» И «ИНОСТРАННЫЙ ЯЗЫК»}

(C) 2018

\author{
Кочетова Наталья Геннадьевна, кандидат физико-математических наук, доцент, \\ декан факультета начального образования
}

Стройков Сергей Александрович, кандидат филологических наук, доцент кафедры иностранных языков Самарский государственный социально-педагогический университет (2. Самара, Российская Федераиия)

Аннотащия. Настоящая статья посвящена проблеме формирования профессиональных компетенций студентов направления подготовки 44.03.05 Педагогическое образование профилей «Начальное образование» и «Иностранный язык». На основе анализа нормативных документов, определяющих требования государства и образовательных организаций (работодателей) к подготовке учителя, авторы работы выстраивают соотношение требований к должности учителя, которые содержатся в федеральном государственном образовательном стандарте основного общего образования, в федеральном государственном образовательном стандарте высшего образования и в профессиональном стандарте «Педагог», обобщают опыт формирования профессиональных компетенций бакалавров на факультете начального образования и на примере ПК-4 представляют покомпонентную характеристику компетенции, а также представляют методики покомпонентной диагностики сформированности данной профессиональной компетенции, отмечают целесообразность введения специальных компетенций по профилю «Иностранный язык», на примере СКИЯ-2 представляют покомпонентную характеристику компетенции. В статье также рассмотрены проблемы формирования профессиональных компетенций студентов направления подготовки 44.03.05 Педагогическое образование профилей «Начальное образование» и «Иностранный язык».

Ключевые слова: компетенция; профессиональные компетенции; специальные компетенции; формирование профессиональных компетенций; покомпонентная характеристика; учитель; педагогическое образование; иностранный язык; стандарт; профессиональный стандарт; методика; диагностика.

Изменения, происходящие в системе образования России, предъявляют высокие требования к подготовке учителя. Процесс формирования профессиональных компетенций студентов направления подготовки 44.03.05 Педагогическое образование профилей «Начальное образование» и «Иностранный язык» регламентируется рядом правовых и нормативных документов, определяющих требования государства и образовательных организаций (работодателей): федеральные государственные образовательные стандарты начального общего образования [1], основного общего образования [2] и среднего (полного) общего образования [3]; единый квалификационный справочник должностей руководителей, специалистов и 